\title{
The Effectiveness of Repetition as Corrective Feedback
}

\author{
Seçıl Büyükbay \\ School of Foreign Languages, Gaziiomanpasa University, Turkey \\ Email: buyukbayscl@hotmail.com \\ Azizollah Dabaghi \\ Department of English, Faculty of Foreign Languages, University of Isfahan, Iran \\ Email: dabaghi@fgn.ui.ac.ir
}

\begin{abstract}
This study investigated the effectiveness of repetition as corrective feedback in terms of its contribution to student uptake and acquisition. Thirty students in two classes, one control and one experimental participated in the study. In order to discover the effectiveness of repetition as corrective feedback, the classes of the control and the experimental group were observed and videotaped. The feedback episodes in the two classes were transcribed, analyzed, and coded. Grammar tests were created based on these feedback episodes. The test results of the two classes were compared. The results revealed that the experimental class, which was exposed to repetition as corrective feedback, achieved higher scores. The findings of the study indicated that repetition as a correction technique is effective in terms of its contribution to uptake and acquisition.
\end{abstract}

Index Terms - repetition, corrective feedback, feedback episodes, uptake, acquisition.

\section{INTRODUCTION}

Corrective feedback is described by Lightbown and Spada (2003) as "an indication to a learner that his or her use of the target language is incorrect."(p.172), and it falls into two categories, explicit or implicit, depending on the way the errors are corrected. Explicit feedback, as Kim and Mathes (2001) stated in their article, refers to the explicit provision of the correct form, including specific grammatical information that students can refer to when an answer is incorrect, whereas implicit feedback, such as elicitation, repetition, clarification requests, recasts and metalinguistic feedback (Lochtman, 2002), allows learners to notice the error and correct it with the help of the teacher. Dekeyser (1993), Lyster and Ranta (1997), and Nassaji and Swain (2002) investigated the effectiveness of corrective feedback; Havranek (1999) aimed to identify the factors that may promote or impede learning through corrective feedback; Kim and Mathes (2001) conducted a study to see whether explicit and implicit feedback benefits learners more, and explored the range, and types of corrective feedback. Long, Inagaki and Ortega (1998) and Lochtman (2002) also investigated the role and effectiveness of implicit feedback in second language acquisition.

Uptake, as Lyster and Ranta (1997) define, is “a student's utterance that immediately follows the teacher's feedback and that constitutes a reaction in some way to the teacher's intention to draw attention to some aspect of the student's initial utterance" (p. 49). In other words, it is simply "learner responses to corrective feedback in which, in case of an error, students attempt to correct their mistake(s)" (Heift, 2004, p. 416). In the domain of language acquisition, which refers to the cognitive process of learning a language, the relationship between uptake and acquisition has been widely explored by language researchers. Uptake is seen as an indicator of students' noticing (Ellis \& Sheen, 2006; Sheen, 2004)) and is considered to be a facilitator of acquisition. The reason that researchers argue that uptake contributes to acquisition depends on their hypothesis that uptake provides students with the opportunity to practice what they have learned and helps them fill in the gaps in their interlanguage (Carroll and Swain, 1993).

There have been some studies conducted to examine the success of uptake and its relation to feedback or acquisition. For example, Ellis, Basturkmen and Loewen (2001), in their study, focused on the success of learner uptake in communicative ESL classrooms. Also, Loewen (2004) examined which characteristics of corrective feedback predicted uptake and successful uptake in terms of learner's noticing or not noticing the error and correcting it as a response to feedback. Ellis, Basturkmen and Loewen (2001), in their study, focused on learner uptake in communicative ESL classrooms, and Tsang (2004) examined the relationship between feedback and uptake in his study.

In addition, one form of corrective feedback, recasts, defined as "the teacher's reformulation of all or part of a student's utterance, minus the error" by Lyster and Ranta (1997, p. 46), has been investigated more than any other type of corrective feedback by researchers (Long, 1996; Mackey, Gass, \& McDonough, 2000; Nabei and Swain, 2002; Philp, 2003). Nevertheless, it was found that recasts were the least effective form of feedback in terms of successful uptake and second language acquisition. Lyster and Ranta (1997), too, studied corrective feedback and learner uptake and the effectiveness of such feedback types as explicit feedback, recasts, elicitation, metalinguistic feedback, clarification requests, and repetition. Their study showed that, although recasts were the most commonly used type, again, it was the 
least effective in terms of uptake and acquisition. Conversely, even though the remaining types were rarely used, they were more likely to be effective.

\section{PURPOSE AND RESEARCH QUESTION}

Despite the fact that repetition has been found to be an effective type of corrective feedback, along with metalinguistic feedback, elicitation and clarification requests (Heift, 2004), its effectiveness has not been investigated separately. Therefore, there is a need to investigate the possible effects of this type of corrective feedback Such an investigation may shed light on the effectiveness of repetition as one corrective feedback type and its possible impact on successful uptake and acquisition. Therefore, the present study aims to shed light on the answer to the following research question:

To what extent does repetition as a form of corrective feedback lead to successful uptake and acquisition?

\section{METHODOLOGY}

\section{A. Participants}

A total of 30 pre-intermediate level learners of two university classes were the participants in this study. The classes were randomly assigned as the control and experimental group. There were 15 students in the control class, and 15 in the other which served as the experimental class. Their age ranged from 17 to 21 . The control group included seven female and eight male students. The experimental group included seven male and eight female students in the experimental group. In order to increase the validity and reliability of findings, the study was conducted with the same teacher for both the control and experimental classes. The teacher was chosen because he is the only teacher who gives grammar courses in two different classes at the same level, which allowed the researcher to compare two classes.

\section{B. Instruments and Data Collection Procedures}

Each class was videotaped for ten hours, and the feedback episodes were identified and coded. After being identified as being focused on grammar, pronunciation, discourse, or vocabulary, the feedback episodes that focused on grammar were coded as student-initiated FFEs or teacher-initiated FFEs (Ellis et al., 2001).Tailor-made grammar tests were constructed based on the feedback episodes observed in the participating classrooms. Grammar items addressed the errors that had prompted the feedback episodes. They focused on the errors for which feedback was provided during the observation period. The main purpose of these items was to find out whether the students successfully learned from the errors that were the focus of the feedback episodes.

The feedback episodes were also used to compare the responses of the students to the feedback and to find out whether repetition as corrective feedback led to more successful uptake and, consequently, more correct answers in the test.

\section{Data Analysis Methods}

The feedback episodes in both classes were identified according the teacher's response to error and the student's response to the feedback. They were then transcribed and coded qualitatively. While identifying, transcribing and coding, the feedback episodes and teacher-student turns were examined according to three categories: error, feedback, and uptake. The episodes were transcribed according to whether the student turns had an error or not, what kind of correction the teacher used, and whether the students repaired or not. The division of the categories was as follows:

\begin{tabular}{|c|c|c|}
\hline Error & Error & No error \\
\hline Feedback: & Feedback & No feedback \\
\hline Feedback: & Explicit feedback & $\begin{array}{l}\text { Implicit feedback (recasts, elicitation, clarification } \\
\text { requests, metalinguistic feedback, repetition) }\end{array}$ \\
\hline Uptake: & No uptake & \begin{tabular}{c|c} 
uptake & successful uptake
\end{tabular} \\
\hline
\end{tabular}

Figure 1. Categories of focus on form episodes

The sentences that the students uttered were identified to see whether they erred or made a grammatical mistake. If the students erred, then the researcher identified the way the participating teacher responded to the error, whether he corrected the errors or not, and how the students responded to the feedback. The feedback types that the teacher used were identified according to Lyster and Ranta's (1997) following feedback types: 


\begin{tabular}{|c|c|}
\hline Explicit correction & Teacher provides the correct form explicitly \\
\hline Repetition & Teacher's repetition of student's erroneous utterance \\
\hline Recasts & Reformulation of student's utterance \\
\hline Metalinguistic feedback & Comments, information, or questions related to the student's utterance \\
\hline Clarification requests & $\begin{array}{c}\text { Indication to students either that their utterance has been misunderstood by the teacher or that } \\
\text { their utterance is ill formed }\end{array}$ \\
\hline Elicitation & Eliciting of what the student has meant or uttered \\
\hline Multiple feedback & Combination of more than one type of feedback \\
\hline
\end{tabular}

Figure 2. Types of corrective feedback

After identifying the feedback type, the researcher transcribed and coded the episodes according to the student's response to feedback, or uptake. Students' uptake was sorted into three categories: no uptake, uptake and successful uptake, as mentioned before. After the identification, transcription and coding process that was applied to episodes in both classes, grammar tests based on these feedback sequences were prepared.

The grammar tests of both classes were quantitatively analyzed and compared to find out whether repetition made a difference in their knowledge of the tested structures. Mean scores of both classes were identified and then compared.

In order to discover whether the students provided the correct answers to the items that originated from their errors, individual students' responses to the questions that were prepared based on their errors in the class were identified. Their responses during teacher-student turns and their answers to that question in the test were compared. The relationship between student uptake and acquisition both in the control class and in the experimental class was explored.

The quantitative data were gathered from grammar tests. The grammar tests were created based on the feedback episodes in both classes, and they were then compared to discover whether repetition is significantly more effective on students' uptake and acquisition.

\section{RESULTS}

In the control class, the observation and the transcription showed that there was a total of 17 errors. The frequencies and classifications of the feedback types in response to these errors can be seen in Table 1 . Three of the errors were ignored by the teacher, and given no feedback, whereas the teacher responded to 14 errors by some kind of feedback. Five of the feedback episodes resulted in 'no uptake', four of them required uptake, and five of them ended in successful uptake. Uptake here refers to "what the student attempts to do with the teacher's feedback" as Lyster and Ranta (1997, p. 49) define. If there is no uptake, then there is no topic continuation. If there is uptake, there is topic continuation; the student errs, and then corrects the error without reformulation of the entire utterance. Successful uptake, on the other hand, refers to the correct reformulation of the sentence by the student.

TABLE 1.

IDENTIFICATION OF FEEDBACK TYPES IN THE CONTROL CLASS AND EXPERIMENTAL CLASS

\begin{tabular}{|c|c|c|}
\hline & Control Class & Experimental Class \\
\hline Number of errors & 17 & 23 \\
\hline Number of errors ignored: & 3 & 2 \\
\hline Feedback type: Explicit feedback & 6 & 2 \\
Recast & 0 & 0 \\
Clarification requests Elicitation & 1 & 0 \\
Metalinguistic f. & 1 & 0 \\
Multiple feedback & 2 & 0 \\
Repetition & 4 & 0 \\
& 0 & 19 \\
& 5 & 3 \\
No Uptake: & 4 & 8 \\
Uptake: & 5 & 10 \\
\hline Successful: & & \\
\hline
\end{tabular}

In the experimental class, 23 errors were identified, as indicated in Table 1. Although the teacher was supposed to use repetition in all of the feedback episodes, he ignored two of the errors. The feedback episodes consisted of repetition provided by the teacher. It was also realized after the coding process that the teacher used explicit feedback two times in the experimental class. However, the feedback episodes in which explicit feedback was given were not used in the grammar tests. The results showed that three of the episodes in the experimental class resulted in no uptake by the students. Eight of the feedback episodes ended in uptake, and ten of them resulted in successful uptake.

\section{ANALYSIS}

\section{A. Correction Episodes}


The focus-on-form episodes in the control class were coded and analyzed according to Lyster and Ranta's (1997) identification of feedback types. The feedback types and the numbers that were used by the teacher are presented, along with the examples taken from the episodes:

TABLE 2.

FEEDBACK TYPES THAT WERE USED BY THE TEACHER IN THE CONTROL CLASS

\begin{tabular}{|c|c|c|c|}
\hline \multicolumn{2}{|c|}{ FEEDBACK TYPES THAT WERE USED BY THE TEACHER IN THE CONTROL CLASS } \\
\hline Valid & clarification request & Frequency & Percent \\
\hline & elicitation & 1 & 7.14 \\
\hline & explicit feedback & 6 & 4.14 \\
\hline & metalinguistic feedback & 2 & 14.28 \\
\hline & multiple feedback & 4 & 28.56 \\
\hline & recasts & 0 & 0 \\
\hline & repetition & 0 & 0 \\
\hline & Total & 14 & 100.0 \\
\hline
\end{tabular}

The results, as indicated in Table 2, showed that explicit correction was used six times, which has a percentage of $42.84 \%$. The other feedback type that was used relatively frequently is multiple feedback. The teacher used this kind of feedback four times in the control class. He used a combination of explicit and metalinguistic feedback once, and he combined clarification request and explicit feedback three times. Below are some examples from the episodes in the control class.

1. Explicit correction:

a) S: What do you think about right now?

T: What are you thinking...

S: .... what are you thinking about. .[Successful uptake]

b) $S$ : Preference to red mean

T: Preference to red means

S: Means [uptake]

c) S: She don't know what Tokat is famous for?

T: She doesn't know..

S:She doesn't know.. [uptake]

d) S: Does she study in the library in the evening? [They are studying The present progressive]

T: Be careful 'in the evening'.

$S:$ [...silence]

T: Is ...

$S$ :Is she studying in the library in the evening? [Successful uptake]

\section{Recasts}

No recasts were observed.

3. Metalinguistic feedback

S1: Is she a good player?

S2: Yes, she is. She is playing pool a lot...

T: Just a minute! Be careful. Is she playing right now, or in general?

S: ...Not playing now..

T: So...?

S: She plays pool a lot. [successful uptake]

\section{Clarification requests}

T: What are you doing there Semra?

$S$ : ...hmm.. He gave me a letter.

T: And?

S: I tear the letter..

T: Sorry, I could not understand you. You tore the letter?

$S$ : .....yes [no uptake]

5. Elicitation

T: Who is sitting next to Ilker?

$S$ : Eray is next to Ilker.

T: Be careful who is sitting next to Ilker?

$S$ : Eray.. is ... sitting... next to Illker [successful uptake]

6. Multiple feedback

a) explicit feedback + clarification request 
S: I am agree with you

T: You agree with me?

$S$ : Yes [no uptake]

b) explicit feedback + metalinguistic feedback

S: Do we say 'Are you needing something else to paint the tables' in a sentence?

T: No, we use 'need', because it's a non-action verb, and we cannot use it with-ing.

$S:$...hmm, $O K$. [no uptake]

c) explicit feedback + clarification request

T: Where is Selin?

$S$ : She is late. She taken the wrong bus.

T: She took the wrong bus?

$S$ : Yes, took. [uptake]

d) explicit feedback + clarification request

T: Why are you laughing Koray?

S: I spell 'happened' when you ask. But wrong!

T: You spelled the word happened incorrectly?

$S$ : Yes! [no uptake]

There were 23 errors that were committed in the experimental class. However, because the teacher ignored two of the errors, only 21 of the errors were transcribed and coded. The only feedback type that was transcribed, coded and used in the grammar test was repetition. Two examples of repetition from the episodes are presented below:

Examples:

1. T: What's your favourite team?

S: My favourite team Beşiktaş

T: Your favourite team? Beşiktaş? Your favourite team Beşiktaş?

S: My favourite team IS Beşiktaş [successful uptake]

2. T: Have you ever been to a Chinese restaurant, Erman?

S: Yes I have. Last night, we have eaten there.

T: Be careful Erman. Last night, we have eaten there? Have eaten?

$S:$...

T: have eaten.. last night?

S: No, we ate there last night.[successful uptake]

\section{B. Grammar Tests}

The quantitative data of the study were gathered through grammar tests, the purpose of which was to measure the effectiveness of repetition on acquisition. The tests were given to both classes after their one-week observation period. Although there were more than 14 feedback episodes in the experimental class, in order to provide equal conditions, the researcher eliminated nine of the episodes, two of which involved explicit feedback in order to provide the classes with the same number of items. Therefore, each grammar test comprised 14 questions created based on the feedback episodes in the respective classes.

However, the students in the two classes were not asked about the same structures due to the discrepant observation periods of the two classes. The questions, which for the control group tested the mastery of present simple, past simple, present perfect, and present progressive tenses, were gap filling questions, some samples of which are presented below.

1. What__ about right now? You look really happy! you, think

2. A preference of blue to red

3. A: in politics? you, interest that you are a calm person. mean

B: Yes, I love politics!

4. A: Game is over!
B: Who the game? win

A: Of course, the teacher!

The questions above show the type of questions that were asked in the grammar test of the control class (the complete test can be seen in Appendix A). The contexts used in the test were the ones in which the students erred. However, the researcher provided some words or sentences when it was difficult for students to find out the answer from the context.

On the other hand, the type of test items used for the experimental class were different from used in the control class. This was due to the fact that the feedback episodes in the control and experimental classes, based on which the grammar tests were made, were different, added to the fact that the experimental class was observed two weeks later than the control class. Moreover, the questions in the experimental class' grammar tests included more difficult structures for the students to master, and/or recognize and, therefore, the grammar test of the experimental class comprised more complex items such as choosing among present perfect, past perfect and simple past, whereas the test of the control class did not. Below are some questions from the grammar test of the experimental class (the complete test can be seen in Appendix B): 
2. __ an elephant? you, ever, ride

3. I have been at this school since the beginning of January. My classes

4. A: Have you eaten in the new Chinese restaurant?

B: Yes I have. We there last night. eat

In order to analyze the data, the scores, the mean scores on the two grammar tests and their standard deviations were calculated and are presented in Table 3.

TABLE 3.

MEAN AND STANDARD DEVIATIONS OF CLASSES

\begin{tabular}{|c|c|c|c|c|c|}
\hline \multirow{2}{*}{ Score } & Class & $\boldsymbol{N}$ & Mean & Std. Deviation & Std. Error Mean \\
\hline & Control class & 15 & 45.22 & 13.94 & 3.60 \\
\hline & Experimental class & 13 & 69.21 & 20.90 & 5.80 \\
\hline
\end{tabular}

Here, it is important to note that the numbers of the students who took the test were not the same. Although the researcher designed the classes so that the number of students would be equal, by asking three students in the control class to attend the classes in the experimental class during the study, two students in the experimental class were not present in the class when the test was taken, which might possibly have affected the results. Because of that, there were 13 students in the experimental class, whereas there were 15 in the other.

As indicated in Table 3, the mean score of the experimental class was higher (69.21) than that of the control class (45.22). In other words, the grammar tests of the two classes showed that the students in the experimental class did better on their test even though their test items were more complex than the items in the test of the control class.

\section{Individual Students' Responses}

In both classes, individual students' responses on the test items were investigated to discover whether they had learned from their errors in the class and the subsequent feedback. In order to reveal this, their errors in class (i.e. the feedback episodes they were directly involved in) and their answers to the test items based on those errors were compared. In order to discover whether the students responded correctly in the grammar test, their names, the feedback type they were exposed to, and whether the episodes they were involved in resulted in uptake or not were identified. After comparing the students' own responses to the question that originated from their own errors, the results of the two classes were also compared to see whether repetition is more beneficial for students to learn from their errors.

The results show that, in the control class, the students who were involved in the episodes that formed the basis of the questions responded to ten out of 14 questions incorrectly. It was also discovered that seven out of the ten test items answered incorrectly had resulted in uptake (whether uptake or successful uptake) during the feedback episodes in classes, as indicated in Table 4.

The table also shows that nine different students made the fourteen errors. The student who made the highest number of errors had a total of five errors. The results of the test showed that he answered three questions incorrectly in the test even though he had corrected these errors during the episodes. More interestingly, his two right answers had resulted in one 'no uptake' and one 'successful uptake'. Another student in the class, who made two errors in the class during the observation period, did not give correct responses in the grammar test either, even though his turns with the teacher resulted in uptake in both episodes. Five out of seven other students who made errors did not respond correctly to the corresponding items on the grammar test, although three students' episodes resulted in successful uptake.

TABLE 4.

INDIVIDUAL STUDENTS' RESPONSES TO FEEDBACK AND ON TEST, CONTROL CLASS

\begin{tabular}{|c|c|c|c|c|}
\hline \multicolumn{5}{|c|}{ Control group } \\
\hline Error & Student & Feedback type & Result of feedback & Result on test \\
\hline 1 & \multirow[t]{5}{*}{ A } & Multiple(exp.+meta.) & No uptake & Correct \\
\hline 2 & & Explicit feedback & Successful uptake & incorrect \\
\hline 3 & & Explicit feedback & Uptake & incorrect \\
\hline 4 & & Explicit feedback & Uptake & incorrect \\
\hline 5 & & Multiple(exp.+ clari.) & Successful uptake & Correct \\
\hline 6 & \multirow[t]{2}{*}{$\mathrm{B}$} & Explicit feedback & Uptake & incorrect \\
\hline 7 & & Metalinguistic f. & Uptake & incorrect \\
\hline 8 & $\mathrm{C}$ & Explicit feedback & Successful uptake & incorrect \\
\hline 9 & $\mathrm{D}$ & Multiple (exp.+ clari.) & No uptake & Correct \\
\hline 10 & $E$ & Metalinguistic f. & Successful uptake & incorrect \\
\hline 11 & $\mathrm{~F}$ & Elicitation & Successful uptake & Correct \\
\hline 12 & $\mathrm{G}$ & Explicit feedback & No uptake & incorrect \\
\hline 13 & $\mathrm{H}$ & Multiple(exp.+ clari.) & No uptake & incorrect \\
\hline 14 & $\mathrm{I}$ & Clarification request & No uptake & incorrect \\
\hline
\end{tabular}


It can be concluded from Table 4 that there is not a clear and significant correlation between uptake and acquisition when the teacher gave his usual responses to errors. In addition, it can also be seen from the table that none of the explicit feedback episodes ended in correct answers in the grammar test. Moreover, the feedback types used in the episodes that resulted in correct responses to test items were elicitation, and multiple feedback consisting of explicit feedback and either metalinguistic feedback or clarification request.

In the experimental class, the errors of the students and their responses to the questions based on their errors were also compared. The feedback episodes of the experimental class consisted of twelve students' errors. However, only ten students' errors were used for designing the test so that the number of the questions could be equalized. As shown in Table 5, the results revealed that four students who committed seven errors in class were able to provide correct answers in the test. Moreover, five of the seven errors that were answered correctly had resulted in uptake (successful uptake or uptake) during the feedback episodes. The results also indicated that the student who made the highest number of errors committed three errors, two of which ended in successful uptake, and one of which resulted in uptake. He responded to two questions correctly, and gave a wrong answer to a question that had resulted in successful uptake in class. As two of the students did not attend the class and take the test, three of the errors could not be analyzed concerning the result of feedback and the result on the test. Interestingly, four questions that were responded to incorrectly in the test originated from the episodes that had ended in two uptakes and two successful uptakes. More interestingly, the students correctly answered the questions that originated from the episodes which had resulted in no uptake in class.

TABLE 5 .

INDIVIDUAL STUDENTS’ RESPONSES TO FEEDBACK AND ON TEST, EXPERIMENTAL CLASS

\begin{tabular}{|c|c|c|c|c|}
\hline \multicolumn{5}{|c|}{ Experimental group } \\
\hline Error & Student & Feedback type & Result of feedback & Result on test \\
\hline 1 & A & Repetition & Uptake & Correct \\
\hline 2 & & Repetition & Successful uptake & incorrect \\
\hline 3 & & Repetition & Successful uptake & Correct \\
\hline 4 & B & Repetition & Successful uptake & $*$ \\
\hline 5 & & Repetition & Uptake & $*$ \\
\hline 6 & $\mathrm{C}$ & Repetition & No uptake & Correct \\
\hline 7 & $\mathrm{D}$ & Repetition & No uptake & $*$ \\
\hline 8 & $\mathrm{E}$ & Repetition & Successful uptake & incorrect \\
\hline 9 & $\mathrm{~F}$ & Repetition & Uptake & incorrect \\
\hline 10 & $\mathrm{G}$ & Repetition & No uptake & Correct \\
\hline 11 & $\mathrm{H}$ & Repetition & Uptake & Correct \\
\hline 12 & & Repetition & Successful & Correct \\
\hline 13 & I & Repetition & Uptake & incorrect \\
\hline 14 & $\mathrm{~K}$ & Repetition & Successful & Correct \\
\hline
\end{tabular}

It can be seen from Table 5 that even though the feedback episodes resulted in uptake or successful uptake in class, the students were not always able to provide correct answers to the items originating from these episodes in the test. However, the test items that originated from the feedback episodes which resulted in no uptake were correctly answered in the grammar test. In the light of these findings, as indicated in Table 5, it can be argued that there is not a clear correlation between the result of feedback and the result on corresponding test items.

In conclusion, the results showed that repetition as corrective feedback ended in ten correct responses in the experimental class whereas the number of correct responses is four in the control class, in which other types of feedback were used by the teacher. Therefore, it can be concluded that although there is not a clear relationship in terms of the result of feedback and the result on the test, repetition as a correction technique appeared to benefit the students more than other types of feedback did.

\section{FINDINGS AND DISCUSSION}

The results revealed that the students in the experimental class, who were exposed to repetition as corrective feedback in response to their errors, did better on their grammar test than the students in the control class, who received the teacher's usual responses to errors, did on their grammar test.

Repetition ended in more uptake moves in the experimental class than the other types of feedback that were used in the control class. It is highly likely that this difference in the two classes was due to the difference in feedback types that were used in the two classes. These results are consistent with the results of Lyster and Ranta's (1997) study in which repetition was one of the feedback types that led to more uptake moves compared with the explicit feedback. These findings are also similar to those of Tsang (2004). In his study, it was also discovered that explicit feedback was the most frequent type of feedback used by the teacher, but repetition was the type of feedback which ended in the highest number of uptake moves.

As for repetition and its relation to acquisition, it can be concluded that repetition led to more correct answers in the test, which showed that when it is compared with other types of feedback, repetition contributes more to acquisition. 
The findings of this study are similar to those of Havranek's (2002) study, in that his study also revealed that implicit feedback contributed to better results on on the test. However, the present study contradicts with Kim and Mathes' (2001) study, in that their study did not result in a difference in terms of acquisition between the group who received explicit feedback and the group who received implicit feedback. This contradiction may be due to the fact that explicit feedback was followed by metalinguistic explanation, and implicit feedback was provided in the form of recasts in their study. As the findings of the present study also indicated, the one time that explicit feedback was accompanied by metalinguistic explanation, it resulted in a correct answer on the grammar test, while explicit feedback alone never resulted in a correct answer.

It can also be argued that, when compared with the control class, not only the students who erred in their utterances but also their peers benefited from repetition as corrective feedback in the experimental class, even though they were not involved in the feedback episodes that formed the basis of the test items. This result is consistent with Havranek's (2002) study, in that his study showed that not only the student who was involved in the feedback episodes but also his/her peers benefited from the episodes and gained high scores in the grammar test. More interestingly, his study also revealed that corrective feedback benefited the peers more than it did the students who were involved in the feedback episodes.

The reason for the higher scores in the experimental class might be due to the time allotted for error correction. When repetition was used as feedback, students were allowed to think, notice their errors, and correct their errors after noticing. This result is consistent with McGuffin et al.'s (1997) study. The findings of their study al so indicated that self-correction benefited the students more than explicit correction did. In the control class in the present study, however, the students were not able to think about their errors, because they were not given the time required, and their teacher corrected their errors whenever they erred. Moreover, it is possible that they were not even aware of the errors they made until they were corrected by their teacher. As the results suggest, explicit feedback was the most frequently used feedback type in the control class, and always resulted in incorrect answers on the test. Explicit feedback alone may have negatively affected the students' ability to learn the structures, which can be the reason for the scores of the students in the control class; however, the one occasion when explicit feedback was combined with metalinguistic feedback ended in a correct answer in the control class. It might be beneficial for students to be corrected by their teacher if he/she uses metalinguistic feedback instead of explicitly correcting the errors without an explanation.

This study also revealed that uptake cannot be regarded as a good predictor of acquisition; i.e. uptake does not necessarily lead to acquisition. The findings showed that not all the successful uptake moves resulted in correct answers in the test, and some 'no uptake' moves ended in correct answers. The results of the present study, in this respect, contradict with Lyster and Ranta's (1'S 997) and Loewen's (2005) studies. The former study revealed that uptake was a good predictor of acquisition as most of the feedback episodes that resulted in uptake moves ended in acquisition. Moreover, Loewen's study also showed that successful uptake was the most significant variable of acquisition among others, such as response, emphasis, timing, complexity and so on. The contradictory results described here are drawn from an extremely small scale study, and the conclusions were drawn based on a small number of feedback episodes, whereas the above-mentioned studies were based on more episodes.

\section{IMPLICATIONS, CONCLUSION, LIMITATION, AND FURTHER RESEARCH}

In the light of the findings mentioned above, some pedagogical implications can be drawn: The first implication is that repetition leads to students' own repair. This is considered to be more beneficial and effective for students' learning (Lyster \& Ranta, 1997; Tsang, 2004) and increases students' critical thinking ability. Also, it can be concluded that instead of explicitly correcting the students' errors and hindering their thinking process, repetition can be used as an implicit correction technique by teachers that might possibly end in success. Furthermore, the teacher repetition may lead to more uptake moves in class. And, in the light of the results of the grammar tests, it can be inferred that when repetition is used as a correction technique in class, it positively affects the results of the tests, which means the students learn better and achieve what they are expected to achieve. In addition to this, grammar tests also revealed that peers also benefited from the students' errors, though they were not actively involved in the feedback episodes which formed the basis of the test items. Because of the fact that repetition is effective in terms of contributing to uptake and acquisition, the teachers can be encouraged to use it more often, and they can be trained to effectively use repetition.

In this study the effectiveness of repetition was explored concerning its benefit to learning grammar. However, repetition can also be used as feedback when the focus is on vocabulary or pronunciation. When the student fails in choosing the correct word or pronouncing it, it will possibly help the student to make her/him aware of the incorrect vocabulary or pronunciation when the incorrect word is repeated by the teacher.

The main limitations of the study resulted from the duration of the study, the number of the participants used, the number of the feedback episodes in classes, and the difficulty of training the teacher to use repetition as corrective feedback in the experimental class. Moreover, different test items were used in both classes; the items were more complex in the experimental class. Furthermore, the students' proficiency levels, although they were thought to be similar, may have also caused different results in the two classes, and it was possible that the learners' learning styles, preferences and abilities may have also affected the results. 
However, studying the effectiveness of repetition as corrective feedback with a larger number of participants and over a longer period of time could be the focus of further research. In addition, studying repetition with students from different proficiency levels might also be an interesting area of further research. Moreover, providing the participating teacher with more time to practice repetition in order to prevent ignoring the errors and wrong use of feedback types could be another alternative for further research. Alternatively, problems in training a teacher to use repetition might be avoided by enlisting a teacher who already uses repetition as corrective feedback.

\section{APPENDIX A The GRAmmar Test OF THE CONTROL Class}

Complete the questions and/or sentences, using the verbs (and pronouns) given, in their proper form:

1 .

2. What something else to paint the tables? you, need

3. A preference of blue to red about right now? You look really happy! you, think

4. A: When the weather is sunny, I feel happier.

B: I with you. Agree

5. at the library in the evening? she, study

6. A: Is she a good player?

$\mathrm{B}$ : Yes, she_pool well. play

7. A: Who is that person next to Isa?

B: Fatih _ next to Isa. sit

8. A: in politics? you, interest

B: Yes, I love politics!

9. She what Tokat is famous for. not, know

10. Unfortunately, she ___ the wrong bus, and she was late for the class this morning. take

11. I___ the word 'happened' when the teacher asked me to. spell

12. I saw a wounded bird in the street, I _ _ it in my hand, and took it to a vet. hold

13. He gave me a letter, but I the letter. tear

14. A: Game is over!

B: Who ___ the game? win

A: Of course, the teacher.

\section{APPENDIX B THE GRAMMAR TEST OF THE EXPERIMENTAL ClasS}

Complete the questions and/or sentences, using the verbs (and pronouns given, in their proper form:

1. A: What did you do in Egypt?

B: I horses. ride

2. an elephant? you, ever, ride

3.

4. A: When ___ you go to Brazil? be

B: I went to Brazil in 2005.

5. A: What did you do in Scotland?

B:I with the girls. dance

6. Since I__ here, I have studied English. come

7. A: What's your favourite team?

$\mathrm{B}:$ My favourite team __ Beşiktaş. be

8. A: Why do you like Tarkan?

B: Because he ___ very well. sing

9. I have been at this school since the beginning of January. My classes

10. Before I came here, I anyone from Zimbabwe. never, meet in January $6^{\text {th }}$. begin

11. I tea in "teachers' house" at the weekend. drink

12. A: Do you have a car?

B: No, I . not

13. A: Have you eaten in the new Chinese restaurant?

B: Yes, I have. We there last night. eat

14. A: Do you like tea?

B: Yes, I . do

\section{APPENDIX C SAMPLE TRANSCRIPTION, CONTROL CLASS INTERVIEW}

Researcher: Hi Nilay! How are you?

Nilay: I'm fine, thank you, and you? 
Researcher: Thanks, I am OK. First of all, I would like to ask why you think I have videotaped your classes. What do you think my aim was?

Nilay: Well, as far as I've heard you are doing your MA, I think that's why..

Researcher: Then, what do you think my study is about?

Nilay: It may be about our teacher's attitudes towards his students?

Researcher: Well, not that one! Now, I will ask you to watch these episodes from your class and another class that I also videotaped. Then, you may realize why I observed your classes. Ready?

Nilay: Yes.

[...]

Researcher: This was the episode from your class. What happened here?

Nilay: The teacher asked a question and Kerim answered it.

Researcher: What happened next?

Nilay:......

Researcher: Did he correctly answer it?

Nilay: No! He did not! He said preference to red mean..

Researcher: And what did the teacher do?

Nilay: He said 'preference to read means". He put 's' there.

Researcher: Perfect! So what did he do?

Nilay: He corrected it.

Researcher: Good! He corrected it. How did he do this?

Nilay: He said 'means'.

Researcher: OK, now let's see the other episode from the other class. Ready?

Nilay: Ready.

[.....]

Researcher: What happened here, Nilay?

Nilay: The student made an error.

Researcher: And?

Nilay: The teacher corrected it!

Researcher: Let's watch it for the second time. OK?

Nilay: $O K$.

Researcher: What happened here?

Nilay: The student made an error, and the teacher said "be careful".

Researcher: And then, what did he say?

Nilay: He said "be careful Ahmet, .. we have eaten there last night?"

Researcher: And?

Nilay: Ahmet said "we ate there last night".

Researcher: So?

Nilay: He corrected it.

Researcher: Exactly! He said "have eaten there last night?" and Ahmet corrected it. Now, can you tell me what the differences between these two episodes are? What happened in the first episode?

Nilay: Kerim made an error and the teacher said "preference to red means.."

Researcher: So the teacher.

Nilay: ..corrected it.

Researcher: And the second episode?

Nilay: Ahmet made an error, the teacher warned him, and said "be careful".

Researcher: And then, what did the teacher say?

Nilay: He said "we have eaten there last night!"

Researcher: Did he correct the error?

Nilay: No, he just repeated the sentence, and Ahmet corrected it.

Researcher: So, Ahmet corrected it, not the teacher, right?

Nilay: Yes!

Researcher: In the first one?

Nilay: The teacher corrected it.

Researcher: In the second one?

Nilay: Ahmet corrected it.

Researcher: How did Ahmet correct his error?

Nilay: Well, the teacher warned him, and repeated the sentence. Then, Ahmet corrected it.

Researcher: Yes, exactly! In your class, your teacher corrected Kerim's error, but in the second the teacher repeated the error, but Ahmet corrected it, right?

Nilay: Yes! 
Researcher: So what do you think about these episodes, and the way your teacher corrected the errors?

Nilay: I think errors should be corrected so that we can realize that we made an error, otherwise we cannot learn. Is it what you wanted to learn?

Researcher: Yes, I just wanted to learn what your opinions were about error correction. Here, you saw two types of correction, in your class the teacher corrected the error, and in the second he repeated the error, and Ahmet corrected it, in fact, I wonder which do you think benefits you more, or which one would you prefer as a correction technique?

Nilay: Well, I personally prefer the second feedback. When the teacher gives us time to think by repeating the same sentence, I can understand that there is something wrong with it. After a while I can realize my error. I think we can learn better when we are given chance to correct our own errors.

\section{APPENDIX D SAMPLE TRANSCRIPTION, EXPERIMENTAL CLASS INTERVIEWS}

Researcher: Hi, Meral, you look happy today!

Meral: Yes, I am.

Researcher: I will not ask why... Well, Meral, do you know why I have videotaped your classes?

Meral: I think you wanted to see how the teacher teaches us.

Researcher: Not exactly, but we'll see. Would you please watch these two episodes from your class and the other class that I also videotaped?

Meral: $O K$.

[...]

Researcher: This was the episode from the other class. So what do you think happened here?

Meral: The teacher and the student were talking to each other.

Researcher: Yes, what did the teacher say at the beginning of the episode?

Meral: He asked a question.

Researcher: Then?

Meral: The student answered it.

Researcher: And, what did the teacher do?

Meral: He repeated the sentence.

Researcher: Did he repeat the same sentence?

Meral: No, he said the correct form of the verb.

Researcher: You mean?

Meral: He said "means".

Researcher: So there was an error in the utterance, right?

Meral: Yes, he said "mean" and the teacher said "means".

Researcher: So, the teacher corrected the error.

Meral: Yes.

Researcher: Let's see the second episode.

Meral: $O K$.

[…..

Researcher: What happened here, this is the episode from your class. Do you recall this?

Meral: Yes, Ahmet said "we have eaten there last night", he didn't take "last night" into account there.

Researcher: You mean that there was an error in his utterance?

Meral: Yes, he should have said we ate there last night.

Researcher: Right, he made an error there and said "we have eaten there last night". Then what did the teacher do?

Meral: He didn't say Ahmet that he made an error.

Researcher: What did he do then?

Meral: He said "be careful", and repeated the sentence a couple of times, and then Ahmet could correct it.

Researcher: That's right. He allowed Ahmet to correct his error by repeating his erroneous utterance. What about the first episode, do you remember what had happened there? What is the difference between the episode from you class and the one from the other class?

Meral: Well, in the first one, the student made an error and said "mean", and the teacher corrected it, but in this episode, when Ahmet made an error, the teacher did not say that he made an error, he just repeated the sentence so that he could understand he made an error.

Researcher: Did Ahmet understand and correct his error then?

Meral: Yes, he understood that he made an error when the teacher emphasized the words "have eaten" and "last night".

Researcher: So, what is the difference?

Meral: The teacher's response to the student, and the student's reply are the differences I guess..

Researcher: So the way the teacher responds to the errors is the difference, and the student's response to the teacher's feedback, right?

Meral: Yes, I guess so. 
Researcher: That's right! So what do you think about these episodes?

Meral: They are different!

Researcher: What else can you say?

Meral: Well..I liked the way he highlighted the error in our class. He didn't say that he made an error. That's good!

Researcher: Well, this leads us to another question then... Which one do you think is better for you, or which one would you prefer when you incorrectly uttered a sentence?

Meral: I would prefer the one in our class.

Researcher: The one with repetition you mean?

Meral: Yes, of course, it is better for us to correct our own errors. So I liked what you asked our teacher to do in our class. He repeated, and repeated, and waited for us until we found the correct answer. In this way, he gave us time to think. He doesn't usually give us time to think about our errors. He corrects it and we correct it. But we often don't know how why, and what we corrected! And sometimes, when we have errors, our friends laugh at us, and correct our errors. It is humiliating for us. But in this way, we correct our own errors and that makes us successful in the eyes of our friends.

\section{APPENDIX E TRANSCRIPTION, TEACHER INTERVIEW}

Researcher: Mr. Şener, you used different feedback types in the two classes, one of them was repetition, and in the other class you gave your usual responses to errors. What do you think about these feedback types you used?

Mr. Şener: In fact, in the past, I didn't use repetition as corrective feedback, and I didn't even think about our responses to students' errors. Now I realize that error correction is a very important part of learning, and we should pay enough attention to errors and to how we correct them

Researcher: So, which one do you think is better concerning the effect on learning?

Mr. Şener: I usually correct my students' errors explicitly, and sometimes provide the explanation of the structures but because of you, I think I will use repetition in the future, because I believe that they learn the grammatical structures by being corrected unconsciously in this way. And later, I talked to students after the observations. They said that they would prefer repetition, and it is beneficial for their learning. I also agree with them after seeing that in prep. 1 [the control class] they still do the same errors, whereas in prep. 4 [the experimental class], they seemed that they learned what we taught; as I repeated their errors and allow them correct their own errors.

\section{REFERENCES}

[1] Carroll, S. \& Swain, M. (1993). Explicit and implicit negative feedback: an empirical study of the learning of linguistic generalizations. Studies in Second Language Acquisition, 15, 357-366.

[2] Dekeyser, R. M. (1993). The effect of error correction on L2 grammar knowledge and oral proficiency. The Modern Language Journal, 77(4), 501-514.

[3] Ellis R., Basturkmen, H., \& Loewen, S. (2001). Learner uptake in communicative ESL lessons. Language Learning, 51(2), 281-318.

[4] Ellis, R., Loewen, S., \& Erlam, R. (2006). Implicit and explicit corrective feedback and the acquisition of L2 grammar. Studies in Second Language Acquisition, 28(2), 339-368.

[5] Havranek G.(1999). The role of corrective feedback in foreign language learning. Retrieved December 5, 2006, from http://www.uni-klu.ac.at/iaa/Department/gh_correction.htm

[6] Havranek, G. (2002). When is corrective feedback most likely to succeed? International Journal of Educational Research, $37(3), 255-270$.

[7] Heift, T. (2004). Corrective feedback and learner uptake in CALL. ReCALL, 16(2), 416-431.

[8] Kim, H. R., \& Mathes, G. (2001). Explicit vs. implicit corrective feedback. The Korea TESOL Journal, 4(1), 57-72.

[9] Lightbown, P., \& Spada, N. (2003). How languages are learnt (Rev. ed.). Oxford, UK: Oxford University Press.

[10] Lochtman, K. (2002). Oral corrective feedback in the foreign language classroom: How it affects interaction in analytic foreign language teaching. International Journal of Educational Research, 37(3), 271-283.

[11] Loewen, S. (2004). Uptake in incidental focus on form in meaning-focused ESL Lessons. Language Learning, 54(1), $153-188$.

[12] Loewen, S. (2005). Incidental focus on form and second language learning. Studies in Second Language Acquisition, 27(3), 361-386.

[13] Long, M. H. (1996). Handbook of second language acquisition. New York: Academic Press.

[14] Long, M. H., Inagaki, S., \& Ortega, L. (1998). The role of implicit negative feedback in SLA: Models and recasts in Japanese and Spanish. The Modern Language Journal, 82(3, Special Issue: The Role of Input and Interaction in Second Language Acquisition), 357-371.

[15] Lyster, R., \& Ranta, L. (1997). Corrective feedback and learner uptake. Studies in Second Language Acquisition 19(01), $37-66$.

[16] Mackey, A., Gass, S., \& McDonough, K. (2000). How do learners perceive interactional feedback? Studies in Second Language Acquisition, 22(4), 471-497.

[17] McGuffin, M. E., Martz, S. A., \& Heron, T. E. (1997). The effects of self-correction versus traditional spelling on the spelling performance and maintenance of third grade students. Journal of Behavioral Education, 7(4), 463-476.

[18] Nassaji,H. \& Swain, M. (2000). A Vygotskian perspective on corrective feedback in L2: The effect of random versus negotiated help on the learning of English articles. Language Awareness, 9(1), 34-51.

[19] Nabei, T., \& Swain, M. (2002). Learner awareness of recasts in classroom interaction: A case study of an adult EFL student's second language learning. Language Awareness, 11(1), 43-63. 
[20] Panova, I., \& Lyster, R. (2002). Patterns of corrective feedback and uptake in an adult ESL class. TESOL Quarterly, 36(4), 573-595.

[21] Philp, J. (2003). Constraints on "noticing the gap". Studies in Second Language Acquisition, 25(01), 99-126.

[22] Sheen, Y. (2004). Corrective feedback and learner uptake in communicative classrooms across instructional settings. Language Teaching Research, 8(3), 263-300.

[23] Ellis, R., \& Sheen, Y. (2006). Exploring the relationship between characteristics of recasts and learner uptake. Language Teaching Research, 10(4), 361-392.

[24] Tsang, W. K. (2004). Feedback and uptake in teacher-student interaction: an analysis of 18 English lessons in Hong Kong secondary classrooms. RELC Journal, 35(2), 187-209.

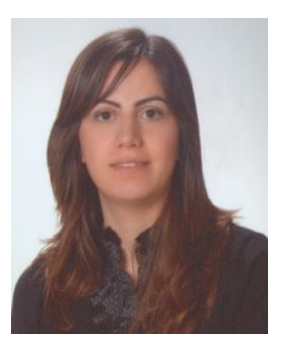

Seçl Büyükbay (b. 1981) is currently an English language instructor at the School of Foreign Languages, Gaziosmanpasa University, Turkey, where she has been working since 2003. Before that, she worked as a high school teacher at Plevne High School following the completion of her BA in English at Gazi University (1999-2003). She received her MA in English from Bilknet University, Turkey in 2006. Her research interests include corrective feedback, form focused instruction and other issues related to second language acquisition.

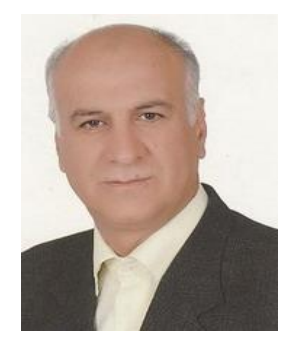

Azizollah Dabaghi (b. 1960, Abadan, Iran) received his doctoral degree in second language acquisition and teaching in 2006 from the University of Auckland, New Zealand after having completed his MA and BA degrees at Isfahan University, Iran in 1996 and 1988 respectively. He also finished his high school and higher diploma education in Sheffield, England, where he spent his life for many years.

Dr. Dabaghi has many years of experience both as a teacher and as an international coordinator of Isfahan University. He has been awarded a number of scholarships and grants from different institutions, including Auckland University Full Doctoral Scholarship and Under Four Year PhD Completion Prize. In 1998, he was awarded with a prize for being the efficient civil servant of the year. He is an assistant professor of English, teaching variety of subjects related to second language acquisition and sociolinguistics as well as psycholinguistics; he is currently researching on the role of corrective feedback, focus on form(s) and task-based learning. He has authored two books and his third and fourth will come out soon. 